\title{
Retracted: The History and Mathematics of the N-Localizer for Stereotactic Neurosurgery
}

\author{
Russell A. Brown ${ }^{1}$, James A. Nelson ${ }^{2}$ \\ 1. Principal Engineer, A9.com 2. University of Washington School of Medicine \\ $\square$ Corresponding author: Russell A. Brown, russ.brown@yahoo.com \\ Disclosures can be found in Additional Information at the end of the article \\ Corresponding author: Russell A. Brown \\ 1. Principal Engineer, A9.com 2. University of Washington School of Medicine \\ How to cite this retraction \\ Brown R A, Nelson J A. (June 23, 2016) Retraction: The History and Mathematics of the N-Localizer for Stereotactic \\ Neurosurgery. Cureus 8(6): r4. doi:10.7759/cureus.r4
}

\section{Retraction Notice}

This article (Brown R A, Nelson J A. (January 16, 2014) The History and Mathematics of the NLocalizer for Stereotactic Neurosurgery. Cureus 6(1): e156. doi:10.7759/cureus.156) is being retracted because it has been replaced by updated and improved articles with additional information (Brown R A, Nelson J A (September 14, 2015) The Origin and History of the NLocalizer for Stereotactic Neurosurgery. Cureus 7(9): e323. doi:10.7759/cureus.323), (Brown R A (October 02, 2015) The Mathematics of Three N-Localizers Used Together for Stereotactic Neurosurgery. Cureus 7(10): e341. doi:10.7759/cureus.341) and (Brown R A, Nelson J A (June 14, 2016) The Invention and Early History of the N-Localizer for Stereotactic Neurosurgery. Cureus 8(6): e642. doi:10.7759/cureus.642). 